\title{
ALLOPURINOL IN PRIMARY GOUT WITH AND AFTER THE ADMINISTRATION OF URICOSURIC AGENTS
}

\author{
BY
}

\author{
G. D. KERSLEY \\ Bath
}

In four cases allopurinol, oroturic acid, and caparase were compared with regard to their effect on plasma uric acid level, uricosuria, and the urinary excretion of oxypurines. In a 6-day trial with each medication it was found that the lowering of plasma and urinary uric acid levels and the increase in urinary oxypurines was considerably greater with allopurinol than with the other medications and that the former appeared to carry less risk and inconvenience (Kersley, 1966). It was therefore decided to carry out a more complete clinical investigation of the value and possible dangers of allopurinol therapy.

\section{Material and Dosage}

A series of 38 patients ( 35 men and 3 women) suffering from primary gout, all with more than 2 years' history of recurrent attacks, has now been under treatment with allopurinol, 25 for over 12 months and four for over 18 months. The routine dosage was $\mathbf{4 0 0} \mathrm{mg}$./day. Seventeen had been previously taking sulphinpyrazone (Anturan) and continued with this drug for the first 6 months; four of them had very severe gout completely uncontrolled by uricosuric agents, and six suffered from gravel or renal colic.

\section{Results}

All these cases were gradually brought under control by the combined use of sulphinpyrazone and allopurinol and the urinary symptoms disappeared where present. In one, the blood urea dropped from 54 to $42 \mathrm{mg} . / 100 \mathrm{ml}$. and the blood pressure from $210 / 130$ to $180 / 100$. In all cases in which tophi were present they healed (if previously discharging) and became smaller. In fifteen of the seventeen cases on the combined treatment it was possible gradually to withdraw the sulphinpyrazone without return of gouty attacks. The average plasma uric acid level in this series was $5.94 \mathrm{mg}$. $/ 100 \mathrm{ml}$. while on sulphinpyrazone only, $3 \cdot 2$ on sulphinpyrazone plus allopurinol, and $4 \cdot 55$ on allopurinol alone (Fig. 1).

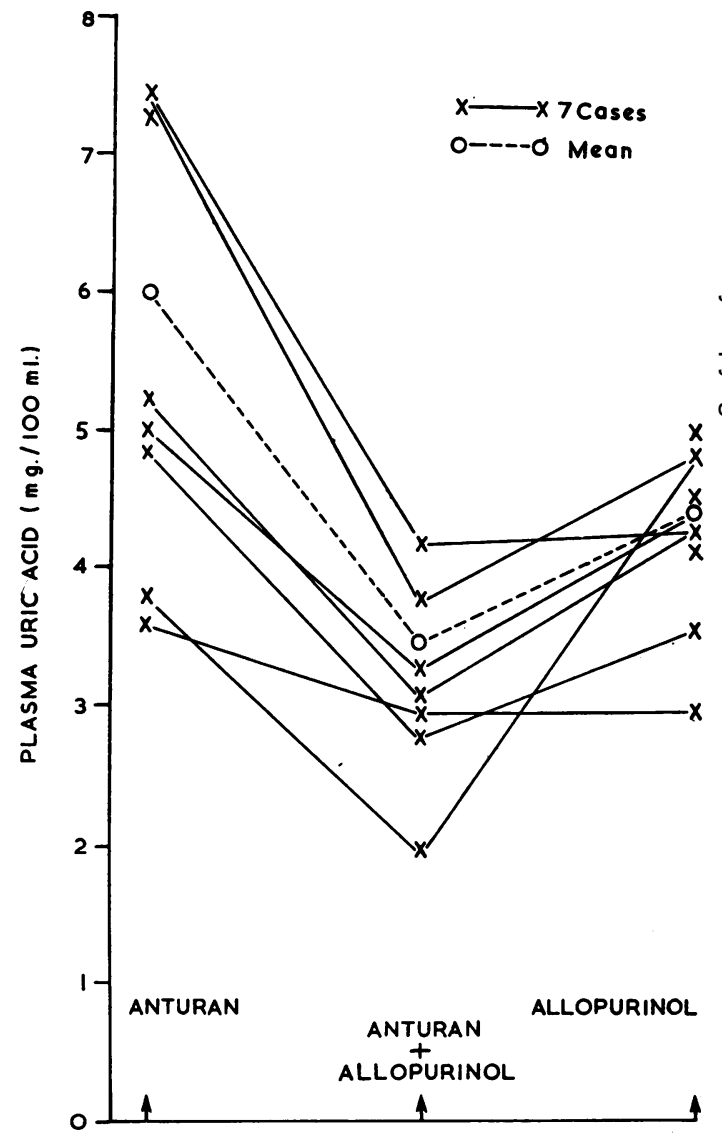

Fig. 1.-Comparison of plasma uric acid levels in patients receiving $400 \mathrm{mg}$./day anturan, $400 \mathrm{mg}$./day allopurinol, and anturan + allopurinol in seven cases, with the means for seventeen cases.

In view of the danger of temporary exacerbation of the gout, other supportive treatment was not 
discontinued until the allopurinol had been administered for 6 weeks, and normally colchicine 1.5 mg./day was given during this period, as has been the practice with uricosuric agents. Though in a few cases there were attacks at this time, they were easily controlled with phenylbutazone.

Tophi have tended to diminish in size, and discharging tophi to heal. Chronic pain and stiffness has decreased.

Toxicity.-This was minimal. Two patients had a slight irritating rash; in one this disappeared on stopping the drug and did not reappear when it was re-started, and in the other the rash was slight and had not become severe enough after 6 months to merit cessation of treatment. In one case there was slight dyspepsia, which disappeared when the tablets were taken with food, and in one the attack rate increased during the first 6 weeks of allopurinol administration and then ceased. Two cases of previously severe gout were involved in accidents with considerable bruising, but even with this trauma no attacks of gout occurred. In one patient, $400 \mathrm{mg}$. allopurinol caused malaise, dizziness, and migraine on three separate occasions, but on $200 \mathrm{mg}$./day there were no toxic symptoms, and the plasma uric acid level fell from $7 \cdot 1$ to $3 \cdot 8 \mathrm{mg}$. $/ 100 \mathrm{ml}$.

In twelve cases serial haematological examination and estimation of serum glutamic oxaloacetic transaminase showed no abnormality, except a transient slight drop in the total white cell count, which recovered without change of dosage.

\section{Termination of Therapy}

In eight cases, after more than 12 months, the allopurinol has been stopped. There is a tendency for the plasma uric acid to rise gradually but not in most cases so rapidly as when uricosuric drugs are discontinued. In only one case, when allopurinol was stopped because of "gastric flu", did the plasma uric acid rise suddenly from $5 \cdot 6$ to $10 \cdot 3$ in 2 weeks, with a resultant acute attack of gout.

The average plasma uric acid in this series was $3 \cdot 4$ $\mathrm{mg}$. $/ 100 \mathrm{ml}$. on allopurinol, $6.5 \mathrm{mg}$. one month after stopping medication, and $7.4 \mathrm{mg} .2$ months later-as compared with original pre-treatment average levels of $8.8 \mathrm{mg}$. $/ 100 \mathrm{ml}$. (Fig. 2). These figures compare well with the rebound often seen on stopping uricosuric therapy. For example, in a typical case controlled for $5 \frac{1}{2}$ years with sulphinpyrazone, the plasma uric acid level rose from $3 \cdot 4$ to

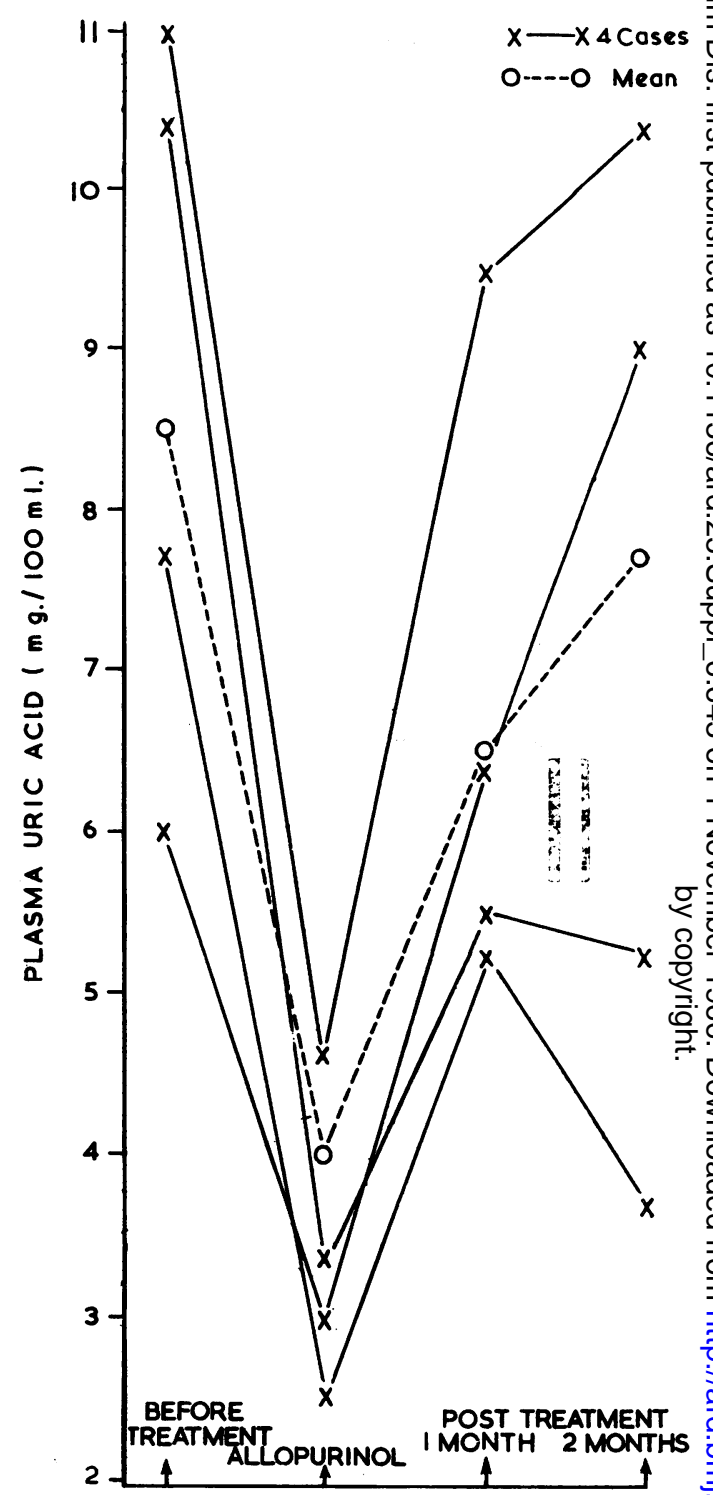

Fig. 2.-Plasma uric acid levels in four cases before, during, and aftef therapy with $400 \mathrm{mg}$./day allopurinol.

$8 \cdot 2 \mathrm{mg} . / 100 \mathrm{ml} ., 2$ weeks after stopping sulphin pyrazone. 